\title{
DIFFUSION OF KNOWLEDGE IN ORGANIZATION FROM CULTURAL AND NETWORK PERSPECTIVE
}

\author{
Agnieszka Marek ${ }^{1}$, Kalina Grzesiuk ${ }^{2}$
}

\begin{abstract}
Diffusion of knowledge is recognized as one of the key factors that determines organizational success in the knowledge-based economy. The research problem concerns the way social networks and organizational culture may influence knowledge sharing among the agents in general. This article presents the review and critical analysis of literature on the diffusion of knowledge from network and cultural perspective. The results of the research show that both social networks and organizational culture might support the flow of knowledge in different ways. The quality and quantity of organizational knowledge depend on different ties between employees, organizational departments, and between an organization and its environment. The conditions for diffusion of knowledge are provided by the knowledge culture, which differs depending on choosing codification or personalization as leading strategy of knowledge management, as well as on set of key organizational values.
\end{abstract}

JEL Classification Numbers: D8, L14, M14, DOI: http://dx.doi.org/10.12955/cbup.v3.590

UDC Classification: 658.3

Keywords: knowledge management, diffusion of knowledge, organizational culture, social networks

\section{Introduction}

Diffusion is defined as a process of spreading "abstract ideas and concepts, technical information, and actual practices within a social system, where the spread denotes flow or movement from source to an adopter, typically via communication and influence" (Wejnart, 2002). Studies of diffusion have been present in scientific research ever since the beginning of the $20^{\text {th }}$ century, but they are still inspiring contemporary scientists. The main reason behind such popularity is its applicability to explaining a wide variety of social phenomena.

The main aim of this article was to present the review and critical analysis of literature concerning diffusion of knowledge as one of the key assets of a contemporary organization. As knowledge management is becoming a more and more important concept in organizational sciences (Scarbrough \& Swan, 2001), the need for identifying the main factors influencing its creation and transference within the organization is increasing. The focus of this paper was on the process of knowledge sharing among the agents and two selected factors determining its effectiveness.

The first one is based upon a relational perspective and concentrates on the impact of social network ties on knowledge transfer on three levels: interpersonal, inter-unit, and inter-organizational. The other is organizational culture and its role as either a catalyst or a barrier to effective learning.

According to Hansen, Mors, \& Løvås (2005), there are three main steps of knowledge sharing in an organization. First, an individual must make a decision to seek knowledge, and that requires awareness of the need for new knowledge. The next step is searching. This stage consists of searching, identifying, and evaluating other knowledge inside and outside of the organization. That means individuals must take into consideration the searching costs of acquiring new knowledge. The amount is usually based upon the time needed to find the information they seek. The last stage is transference of knowledge across the organization and its units. This is the step that is taken into consideration in this article.

One of the most important issues regarding diffusion of knowledge in organizations is the distinction between explicit (codified) and tacit (personalized) knowledge. Boone \& Ganeshan (2008) described the former as easily captured in words, rules, or norms and, by that, easy to organize and communicate

\footnotetext{
1 Agnieszka Marek, PhD, Faculty of Social Sciences, John Paul II Catholic University of Lublin, agnieszka.marek@kul.pl

2 Kalina Grzesiuk, PhD, Faculty of Social Sciences, John Paul II Catholic University of Lublin, kalina.grzesiuk@kul.pl
} 
through various means. Tacit knowledge is created by individuals and their experiences. This kind of knowledge is very difficult to codify and share. Effective transfer of tacit knowledge usually requires the support of organizational climate and personal interactions that encourage building of mutual understanding and trust between individuals.

\section{The social network perspective}

Social networks, in an organizational context, are an important subject of research, especially in the context of information flow and knowledge sharing. Researchers investigate social network phenomenon on three levels. First, its significance can be seen on a dyadic level as personal relations between individuals. Organizations consist of single persons and each of them has his or her own network of ties. Such relations can arise as a result of being a member of a formal group or can be based upon non-formal, social interactions members have with each other within or outside the organization. Second, the division of labor implies working in specific units and departments. In order to achieve effective results on an organizational level, they have to cooperate with each other. This interdependence imposes creating a network of ties that allows informational flow between departments in the organization. This makes studying relations between groups in organizations from the network perspective an important aspect of knowledge diffusion analysis. Third, social networks influence organizational strategies on the macro level, as firms are inevitably connected with other partners in their environment. Supporting economic relations, both competitive and cooperative, with social relations makes exchanging knowledge and carrying out transactions on the market easier, faster, and cheaper. Explaining the complexity of knowledge diffusion process in organizations through the scope of social network requires synthesizing all three levels of analysis.

\section{Interpersonal ties}

Social network ties among members of an organization are basically similar to relations each of them has in the social environment. However, there is one significant difference. As Lincoln \& Miller (1979) observed, in social life, one can more arbitrarily choose people to be connected to and decide whether to keep relations with other people. In the organizational life, this freedom is limited. There are restrictions imposed by work interdependence and organizational structure. That may mean being forced to maintain some relationships, even if it causes some psychological and emotional discomfort.

An individual's social network ties can influence the diffusion of knowledge within the organization. One of the most important research issues in this area is the way in which the strength of social network ties determines the effectiveness of such transfer. Ties between individuals can be described as weak or strong. This distinction was introduced by Granovetter (1973) in the context of social and economic life but was also verified in the organizational setting (Brass, Galaskiewicz, \& Greve, 2004).

These two types of ties were distinguished on the basis of the combination of time spent together, the emotional intensity, the intimacy, and reciprocal services. Both of them influence the diffusion of knowledge in an organization, but each offers different benefits. Strong ties connect people who are close to each other. This means that they share information and knowledge on a regular basis. Frequent and close contacts build trust and lead to creating common perceptions and interpretations of reality. These are necessary prerequisites for the diffusion of tacit knowledge. People close to us are also easier to access (Krackhardt, 1992) and are more willing to give useful information (Tsai \& Ghoshal, 1998).

Although strong ties are significant for sharing specific knowledge, they usually cannot facilitate acquiring novel information. This is because in such close and frequent contacts, it is likely that the other person already has it. To gain access to new knowledge, one must reach out to other, external networks. Weak ties are more appropriate for this purpose because they form bridges connecting 
people with different social networks (Granovetter, 1973), thereby enabling access to entirely new pools of information.

\section{Inter-unit ties}

Analysis of intra-organizational ties often focuses on relations between groups of employees. Formal groups appear as a result of a work breakdown structure and are clearly visible in the organizational scheme. However, there are also informal groups of individuals built upon their social relations, which are not necessarily connected with work. These groups tend to be more homogenous than the formal ones, which can be a result of a social phenomenon called homophily (Lazarfeld \& Merton, 1954). It has a double-sided effect on individuals. First, people usually make friends with others who are in some ways similar to them; second, the more time they spend together the more alike they become. Homogenous groups are important in knowledge sharing because these close relations build trust and create common cognitive models. That, in turn, facilitates sharing of difficult-to-code tacit knowledge. Some researchers indicate that they are also more effective in sharing highly complex knowledge (Hansen, 1999; Levin, Cross, Abrams, \& Lesser, 2002). However, there is one problem related to the homogenous groups, and it concerns the pool of available information. Concentrating on knowledge shared within the group can lead to decreasing ability to acquire new ideas that usually come from external networks.

In reference to this area of research, Oh, Chung, \& Labianca (2004) introduced a concept of group social capital. The authors defined this term as a configuration of members' social relations with others within the group and within the organization as a whole - ensuring access to required resources. Existence of such social interaction ties stimulates trust and leads to an exchange of knowledge among various departments (Tsai \& Ghoshal, 1998). Social network ties of individuals as members of various groups in an organization function as bridges enabling access to new information and knowledge available outside of a homogenous group. According to Hansen (1999), having a network consisting predominantly of weak ties can be beneficial for exchanging explicit knowledge; however, in the case of tacit knowledge divisions with more strong ties are more efficient.

\section{Inter-organizational ties}

Contemporary organization often try to achieve competitive advantage on the market by implementing a strategy called networking that requires developing networks of interconnected partners. Galaskiewicz (1985) mentions three main reasons why firms choose this strategy: access to necessary resources, reducing uncertainty, and increasing the legitimacy of their actions in the eyes of shareholders and various institutions in the environment.

The structure of these networks consists of two main types of ties. On the basis of Powell's (1990) classification of transactions, Uzzi (1997) distinguished between arm's length and embedded ties. The former is more common on the market and can usually be found when transactions between partners are nonrecurring and not supported by any kind of non-economical relation. Embedded ties usually connect partners who share a history of transactions and expect to continue them in the future; shadow of the past and shadow of the future as Batenburg, Raub, \& Snijders (2003) called them, and in many ways they are very similar to Granovetter's strong ties. Such relations are very important for organizations because they build trust between partners, allowing a precise flow of information and encourage creating mutually beneficial solutions to emerging problems.

Knowledge and information shared with closely tied partners are usually more unique and would be unavailable to access from any other source (Ahuja, 2000). Embedded ties allow the exchange of more advanced technological knowledge that is usually tacit and allows the reduction of the time needed for creating new developments. As Cowan \& Jonard (2004) observed, most industries have a stable 
network of partners they informally share knowledge with. That includes trading information with competitors, but, in this case, it is always based on reciprocity.

However, just as in the case of interpersonal and intergroup ties, the network structure needs to be properly managed because excessive involvement in embedded ties might pose a threat to the organization. Too much openness can leave the firm vulnerable to opportunistic behaviors of unfair partners (Larsson, Bengtsson, Henriksson, \& Sparks, 1998).

\section{Organizational culture - support or barrier for diffusion of knowledge?}

Each organization has its own unique culture that is the basis of understanding the reality, making decisions, and choosing the best way of acting in the organization. That culture may either facilitate the transfer of knowledge or hinder it, depending on the key values on which it is built. There is no one model of culture that is ideal for supporting the knowledge transfer. More importantly, some traits of the culture depend on the strategy that an organization chooses for managing knowledge.

According to Hansen, Nohria, \& Tierney (1999), there are two main approaches to sharing valuable knowledge in an organization: codification strategy and personalization strategy. The former is tightly connected to reusing explicit knowledge that is codified by employees and stored in electronic databases. It requires a huge investment in IT technologies that provide efficient tools for accumulating organizational knowledge and making its resources accessible for each member of the organization, even without the contact with a person who codified it (Hansen et al., 1999; Hansen \& Nørbjerg, 2005). The most important aspect of personalization strategy is the relations between employees who share their tacit knowledge with others in order to create the most appropriate solution of emerging problems. The role of IT is completely different here as it is used to identify experts in a particular field of knowledge who are able to help with the analyzed situation (Hansen et al., 1999; Venkitachalam, Scheepers, \& Gibbs, 2004). These strategies are complementary and choosing one does not exclude another, but managers should decide on one dominant strategy and incorporate it with the second one in an 80/20 proportion. Emphasizing the wrong strategy or using both at the same level of importance may "quickly undermine a business" (Hansen et al., 1999).

Codification and personalization strategy focus on different aspects of knowledge sharing, which means that they need different conditions and tools for its transference. This requires some specific traits of an organizational culture. Taking into consideration the Competing Values Framework (Cameron \& Quinn, 2011), one may think that the best conditions for codification strategy are provided by bureaucratic culture, and the personalization strategy may be developed in a clan-like organizations. This view is an unjust simplification.

In general, the culture of knowledge should be based on trust, which enables cooperation; promote a positive outlook on knowledge that requires leading by example instead of just verbal incentives; support innovativeness and openness in its wide sense; remove all barriers that hinder flow of knowledge (Davenport \& Prusak, 1998; Sveiby \& Simons, 2002; Marek, 2010; 2011). These features, however, are of different importance in organizations with different knowledge strategies.

Organizational culture itself, as a way of understanding reality within the organization, is really important if leading strategy is codification. Through this strategy, which is perceived as "people-todocument" approach, knowledge is "extracted from the person who developed it, made independent of that person, and reused for various purposes" (Hansen et al., 1999). It is used to share explicit knowledge and requires its retrieval that consists of searching and decoding processes. IT devices enable a seeker to find needed piece of information, but deciphering the information and gaining its meaning in specific context is much more difficult (Gammelgaard \& Ritter, 2005). The culture might help in bridging the contextual gap between the sender and the receiver through providing shared 
meaning for organizational symbols, behavior, and proceedings. Codification strategy is the best way for organizations that offer mature, standardized products, which require using proven methods and copying existing solutions. It leads to minimizing costs and the time needed for inventing offer that is accurate for a specific client (Hansen \& Nørbjerg, 2005). Using databases and contributing to them should be rewarded through motivational system as expected behavior People must be trained on how to reuse knowledge and implement the chosen solution (Hansen et al., 1999). Taking into consideration all mentioned aspects of the codification strategy, the most important values for the organization that uses it include: shared organizational context, easy access to stored knowledge, open communication between employees that minimize the distance, quick response on customers' needs, standardization of procedures and problems' solutions.

Diffusion of knowledge looks different in the "people-to-people" approach, which is the personalization strategy. Personalization requires direct communication among employees as its task is to enable the sharing of tacit knowledge that is embedded in peoples' minds. The role of IT devices is not as significant as in codification because they are not used for knowledge diffusion but rather for seeking people with needed knowledge, explaining the problem in brief, and finding the best solution (Hansen et al., 1999; Jahn \& Nielsen, 2012). In such organizations, employees often create communities of practice within which they can deepen their knowledge on a specific issue by interacting with others (Wenger, McDermott, \& Snyder, 2002). The group shares the knowledge to invent a unique solution which fulfills the needs of a particular customer. That is one of the assumptions of the personalization strategy. Thanks to highly customized result, their company may be able to maintain high profit margins. The more often used method of training is one-on-one mentoring. Employees are expected and rewarded for sharing tacit knowledge with their cooperators and for the original ideas that meet the clients' expectations (Hansen et al., 1999). The organizational culture in which the leading strategy of knowledge management is personalization should be built on the following key values: trust that enables sharing of tacit knowledge and cooperation, openness that leads to creating of unique solutions, direct communication, and facilitation of both strong and weak ties among employees.

\section{Conclusion}

To sum up, diffusion of knowledge depends highly on members of an organization, their will to sharing both explicit and tacit knowledge, and interactions between them. To share knowledge, people build ties on different organizational level. Personal relations between individuals lead to building trust and creating shared meanings of reality (strong ties) and enable access to entirely new information by bridging people with different social networks (weak ties). Inter-group ties facilitate knowledge diffusion between departments in the organization and building networks with other organizations on the market, which enable exchange of knowledge with the environment and faster and cheaper access to information outside an organization. Another important factor that creates conditions supportive of knowledge diffusion is the organizational culture. Culture also provides the common understanding of organizational reality, but it may facilitate or hinder the flow of knowledge. This article is focused on the knowledge culture that supports interactions among employees and promotes behavior that facilitates knowledge sharing. Although there is no definite type of knowledge culture as each organization is unique in their field, one may identify the key values that are vital for knowledge diffusion. The set of values and their importance differ depending on whether codification or personalization is chosen as the leading strategy for knowledge management. This is why managers of a particular organization have to decide which assumptions, values, and behaviors should be promoted within their company. 


\section{References}

Ahuja, G. (2000). Collaboration networks, structural holes, and innovation: A longitudinal study. Administrative Science Quarterly, 45, 425-455. doi: 10.2307/2667105

Batenburg, R. S., Raub, W., \& Snijders, C. (2003). Contacts and contracts: dyadic embeddedness and the contractual behavior of firms. Research in the Sociology of Organizations, 20(1), 135-188. doi: 10.1016/S0733-558X(02)20006-3

Boone, T., \& Ganeshan, R. (2008). Knowledge acquisition and transfer among engineers: Effects of network structure. Managerial and Decision Economics, 29(5), 459-468. doi:10.1002/mde.1401

Brass, D., Galaskiewicz, J., \& Greve, H. (2004). Taking stock of networks and organizations: A multilevel perspective. Academy of Management Journal, 47(6), 795-817. doi: 10.2307/20159624

Cameron, K. S., \& Quinn, R. E. (2011). Diagnosing and changing organizational culture: Based on the competing values framework. John Wiley \& Sons.

Cowan, R., \& Jonard, N. (2004). Network structure and the diffusion of knowledge. Journal of Economic Dynamics and Control, 28(8), 1557-1575. doi:10.1016/j.jedc.2003.04.002

Davenport, T. H., \& Prusak, L. (1998). What do we talk about when we talk about knowledge. Working knowledge: How organizations manage what they know.

Galaskiewicz, J. (1985). Interorganizational relations. Annual review of sociology, 281-304. doi: 10.1146/annurev.so.11.080185.001433

Gammelgaard, J., \& Ritter, T. (2005). The knowledge retrieval matrix: codification and personification as separate strategies. Journal of Knowledge Management, 9(4), 133-143.

doi: 10.1108/13673270510610387

Granovetter, M. S. (1973). The strength of weak ties. American journal of sociology, 1360-1380. doi: 10.1086/225469

Hansen, M. T. (1999). The Search-Transfer Problem: The Role of Weak Ties in Sharing Knowledge across Organization Subunits. Administrative Science Quarterly, 44(1), 82. doi: 10.2307/2667032

Hansen, M. T., Mors, M. L., \& Løvås, B. (2005). Knowledge sharing in organizations: Multiple networks, multiple phases. Academy of Management Journal, 48(5), 776-793. doi: 10.5465/AMJ.2005.18803922

Hansen, M. T., Noria, N., \& Tierney, T. (1999). What's Your Strategy for Managing Knowledge? Harvard Business Review, 77(2), 106-116.

Hansen, B., \& Nørbjerg, J. (2005). Codification or Personalisation-a simple choice. In Proceedings of the 28th Information systems Research seminar In Scandinavia, Kristiansand, Norway.

Jahn, K., \& Nielsen, P. A. (2012). A Vertical Approach to Knowledge Management: Codification and Personalization. Enhancing the Modern Organization through Information Technology Professionals: Research, Studies, and Techniques: Research, Studies, and Techniques, 216.

Krackhardt, D. (1992). The strength of strong ties: The importance of philos in organizations. In N. Nohria \& N. E. Friedkin (Eds.), Networks and organizations: Structure, form, and action, 216- 239.

Larsson, R., Bengtsson, L., Henriksson, K., \& Sparks, J. (1998). The Interorganizational Learning Dilemma: Collective Knowledge Development in Strategic Alliances. Organization Science, 9(3), 285-305. doi: 10.1287/orsc.9.3.285

Lazarsfeld, P. F., \& Merton, R. K. (1954). Friendship as a social process: A substantive and methodological analysis. Freedom and control in modern society, 18(1), 18-66.

Levin, D. Z., Cross, R., Abrams, L. C., \& Lesser, E. L. (2002). Trust and knowledge sharing: A critical combination. IBM Institute for Knowledge-Based Organizations, 1-9.

Levin, D., \& Cross, R. (2004). The strength of weak ties you can trust: The mediating role of trust in effective knowledge transfer. Management Science, 50(11), 1477-1490. doi: 10.1287/mnsc.1030.0136

Lincoln, J. R., \& Miller, J. (1979). Work and Friendship Ties in Organizations: A Comparative Analysis of Relation Networks. Administrative Science Quarterly, 24(2), 181-199. doi: 10.2307/2392493

Marek A. (2010). Rola kultury organizacyjnej w tworzeniu i upowszechnianiu wiedzy [The role of organizational culture in the creation and dissemination of knowledge. Knowledge]. Wiedza. Między słowem a obrazem. M. Zemło, A. Jabłoński, J. Szymczyk (ed.), Lublin: Wydawnictwo KUL, 267-280.

Marek A. (2011), Kultura wiedzy jako czynnik wspomagający rozwój zawodowy urzędników. [Culture of knowledge as a factor enhancing the professional development of officials]. Nowe tendencje w zarzadzaniu, t. II [New trends in management, vol. II]. M. Pawlak (ed.), Lublin: Wydawnictwo KUL, 239-254. 
Oh, H., Chung, M.-H., \& Labianca, G. (2004). Group Social Capital and Group Effectiveness: the Role of Informal Socializing Ties. Academy of Management Journal, 47(6), 860-875. doi: 10.2307/20159627

Powell, W. W. (1990). Neither Market nor Hierarchy: Network Forms of Organization. Research in Organizational Behavior, 12, 295-336.

Scarbrough, H., \& Swan, J. (2001). Explaining the diffusion of knowledge management: The role of fashion. British Journal of Management, 12(1), 3-12. doi: 10.1111/1467-8551.00182

Scheepers, Rens, Krishna Venkitachalam, and Martin R. Gibbs. (2004). Knowledge strategy in organizations: refining the model of Hansen, Nohria and Tierney. The Journal of Strategic Information Systems 13.3: 201-222.

Sveiby, K. E., \& Simons, R. (2002). Collaborative climate and effectiveness of knowledge work-an empirical study. Journal of Knowledge Management, 6(5), 420-433. doi: 10.1108/13673270210450388

Tsai, W., \& Ghoshal, S. (1998). Social capital and value creation: The role of intrafirm networks. Academy of Management Journal, 41(4), 464-476. doi: 10.2307/257085

Uzzi, B. (1997). Social structure and competition in interfirm networks: The paradox of embeddedness. Administrative science quarterly, 35-67. doi: 10.2307/2393808

Wejnert, B. (2002). Integrating Models of Diffusion of Innovations: A Conceptual Framework. Annual Review of Sociology, 28(1), 297-326. doi: 10.1146/annurev.soc.28.110601.

Wenger, E., McDermott, R. A., \& Snyder, W. (2002). Cultivating communities of practice: A guide to managing knowledge. Harvard Business Press. 